\title{
Diagnosis and Analysis of the Transformer Winding Deformation Fault
}

\author{
Li Xinyu, Wang Qinghao, Liu Peng, Pang Yanjun, Li Simin, Li Yan, Zhang Ning, \\ Wang Enlu, Lin Bin, Yue Yangzhuo, Liu Chenyang, Liu Qiang \\ Fushun Power Supply Company, Liaoning Electric Power Company Limited, State Grid, China,
}

fushunpowersupply@163.com

Keywords: transformer; winding; deformation; test

\begin{abstract}
Together export transformer short-circuit accident analysis for a $66 \mathrm{kV}$ substation, analyze a variety of test methods $66 \mathrm{kV}$ transformer winding deformation, and the advantages and disadvantages of these test methods are discussed in detail, based on capacitance changes proposed transformer winding and with the frequency response method and short-circuit impedance, chromatographic analysis to accurately determine whether the transformer winding deformation methods.
\end{abstract}

\section{Introduction}

With the development of power system capacity is increasing in China, the short-circuit capacity increased, at the same time, the operation environment of the substation's outlet and inlet line is not optimistic, all kinds of the over voltage occurs, due to external short-circuit with the transformer winding deformation, and it is the common faults during the operation of the transformer. Transformer suddenly occurs short-circuit fault, in transformer winding through the large short-circuit current, the short-circuit current interact with the leakage magnetic field generate large electric power force. Although the transient duration is very short, the transformer still is damaged. After the transformer is subjected to sudden short-circuit, if for the slight deformation is not found and repair in time, so after the transformer is subjected to repeated impact, the cumulative effect will cause the damage of the transformer. Therefore, in the process of operation, when the transformer occurs external short-circuit accident, how to quickly detect the existence of transformer winding deformation and deformation degree, it is important condition to guarantee the safe operation of the transformer[1-3].

On September 22nd 2012, there was construction accident of a $10 \mathrm{kV}$ cable dig occurred within a $66 \mathrm{kV}$ substation near the place, caused the No. 2 main transformer shutdown in $66 \mathrm{kV}$ substation , after sampled and did the chromatographic analysis of the transformer and there were no abnormal, the transformer was in operation. On September 28, 2012, due to construct the $10 \mathrm{kV}$ cable dig in rain caused by three-phase short-circuit accident, the No. 2 main transformer did differential protection action, caused the No. 2 main transformer in $66 \mathrm{kV}$ substation shutdown again. Called the protection record of the scene background computer and founded the No. 2 transformer was impact of the near outlet short-circuit current about $13 \mathrm{kA}$,the fault clearance time was $22 \mathrm{~ms}$. The following analysis of various testing methods about the $66 \mathrm{kV}$ main transformer winding deformation, and make a detailed discussion on the advantages and disadvantages of these test methods[4, 5].

\section{Winding together with the bushing capacitance and dielectric loss test}

No. 2 main transformer type in $66 \mathrm{kV}$ substation is SZ11-31500/66; the rated voltage: $66 \pm / 8 \times 1.25 \% / 10.5 \mathrm{kV}$, the rated current: $275.6 / 1732.1 \mathrm{~A}$, the factory time is in August,2011. After transformer factory, the winding capacitance is basically a certain. As long as the transformer has not received the short-circuit impact, even if there are effects of temperature, humidity condition, the capacitance change is very small. Suffered outlet short-circuit for the transformer, if the change of the winding capacitance is very big, the winding has deformation; the capacitance changes little, the transformer without deformation. In October 9, 2012,did the winding together with bushing capacitance and dielectric loss test for the transformer, the test data are shown in Table 1. 
Table 1 Transformer 2 times test data

\begin{tabular}{|c|c|c|c|c|}
\hline Test time & Test connection & $C_{\mathrm{X}}(\mathrm{pF})$ & $\operatorname{Tan} \delta \%_{\mathrm{t}}$ & $\operatorname{Tan} \delta \%\left(20^{\circ} \mathrm{C}\right)$ \\
\hline \multirow{3}{*}{ 2011.09.04 } & $\begin{array}{l}\text { the high voltage winding to the low } \\
\text { voltage winding and the ground }\end{array}$ & 8623 & 0.279 & 0.2203 \\
\hline & $\begin{array}{l}\text { the low voltage winding to the high } \\
\text { voltage winding and the ground }\end{array}$ & 14490 & 0.271 & 0.2140 \\
\hline & $\begin{array}{l}\text { Between the high voltage winding and } \\
\text { the low voltage winding }\end{array}$ & 5731 & 0.247 & 0.1950 \\
\hline \multirow{3}{*}{ 2012.10.09 } & $\begin{array}{l}\text { the high voltage winding to the low } \\
\text { voltage winding and the ground }\end{array}$ & 7941 & 0.333 & 0.41077 \\
\hline & $\begin{array}{l}\text { the low voltage winding to the high } \\
\text { voltage winding and the ground }\end{array}$ & 15540 & 0.665 & 0.82031 \\
\hline & $\begin{array}{l}\text { Between the high voltage winding and } \\
\text { the low voltage winding }\end{array}$ & 5051 & 0.256 & 0.31579 \\
\hline
\end{tabular}

Through the test found the high voltage winding to the low voltage winding and the ground capacitance and the handover test numerical rate reached to $7.91 \%$;the low voltage winding to high voltage winding and the ground capacitance and handover test numerical rate reached 7.24\%; For analyzing what part is abnormal, the measure results will conversion for the winding itself capacitance, such as in Table 2. The low voltage winding to the iron and the ground capacitance compared with the commission is increased by $19 \%$, it shows that the low voltage coil is squeezed by the short-circuit force, trending towards the core, in addition, the high voltage and low voltage winding to ground capacitance also change obviously, between the winding capacitance change is very big. The high voltage winding to the ground capacitance change little, it shows that the high voltage winding is normal and no deformation.

Table 2 Decomposition and conversion for the winding capacitance compared with commission test $\mathrm{pF}$

\begin{tabular}{cccc}
\hline the test site & This test & commission test & rate of change /\% \\
\hline $\begin{array}{c}\text { The high voltage winding } \\
\text { The low voltage winding }\end{array}$ & 2890 & 2892 & 0.6 \\
between the winding & 10489 & 8759 & 19.0 \\
\hline
\end{tabular}

\section{Short-circuit impedance test}

The short-circuit impedance of transformer is the internal equivalent impedance of the transformer in full load. The reactance components of the short-circuit impedance is usually said to the leakage reactance of the transformer or short-circuit reactance Xk, Xk relates to the geometric position of the transformer input winding and output winding. $\mathrm{Xk}$ is a function of the winding leakage flux, so as long as the winding produce displacement or deformation, the short-circuit reactance Xk will produce change, due to in short-circuit impedance test at the same time, whether in the rated current, or the small current in the low voltage, the transformer core flux is not large, which are far from the saturated magnetic flux, so Xk doesn't relate with the applied voltage and current. After the transformer is subjected to short-circuit current impact, the measured short-circuit 
impedance compare with the data of before the operation, the reference standards for the relative change is not more than $2 \%$, in addition, the measured impedance values can also compare with the nameplate values. Therefore secondary winding short-circuit, Applying voltage to the transformer primary winding , the applied voltage is $216 \mathrm{~V}$, the measured short-circuit impedance value is $9.48 \%$, the nameplate value is $9.09 \%$.The change rate reach to $4.29 \%$.Rules are the same test instrument the same test method for the measured short-circuit impedance of the transformer winding comparing to the previous: the change rate is in $1 \% \sim 2 \%$, it shows that winding deformation is no obvious; the change rate is in $2 \% \sim 4 \%$,it can be thought of winding deformation is obvious; More than $4 \%$ should quit from the operation and find out the reason.

\section{Frequency response analysis test}

The main transformer is in transition, had to save frequency response characteristic curve of each winding, the frequency response characteristics curve of after the fault compare with the 'fingerprint' of the transition reserved, the high voltage winding frequency response curve of the three phase's difference is not big, more is better, but the low voltage winding frequency response curve of the three phase's difference is very obvious, the correlation is poor. Can be seen from Figure 1 that after short circuit Lca, Lbc, Lab curve compared, there are differences in the frequency distribution position and the distribution number of the peaks and troughs, namely the amplitude frequency response characteristics of the three-phase winding's consistency is bad, all the relevant test results for the low voltage $\mathrm{C}$ phase winding showed obvious anomalies, the winding frequency response indicate the $\mathrm{C}$ phase winding deformation. For the No. 2 main transformer, the minimum correlation coefficient of the low voltage winding deformation is 0.86 , the low frequency value is large than 0.6 and less than 1 should be obvious deformation. But the transition's value is good. So, it can be judged the transformer winding deformation after the sudden short-circuit current impact.

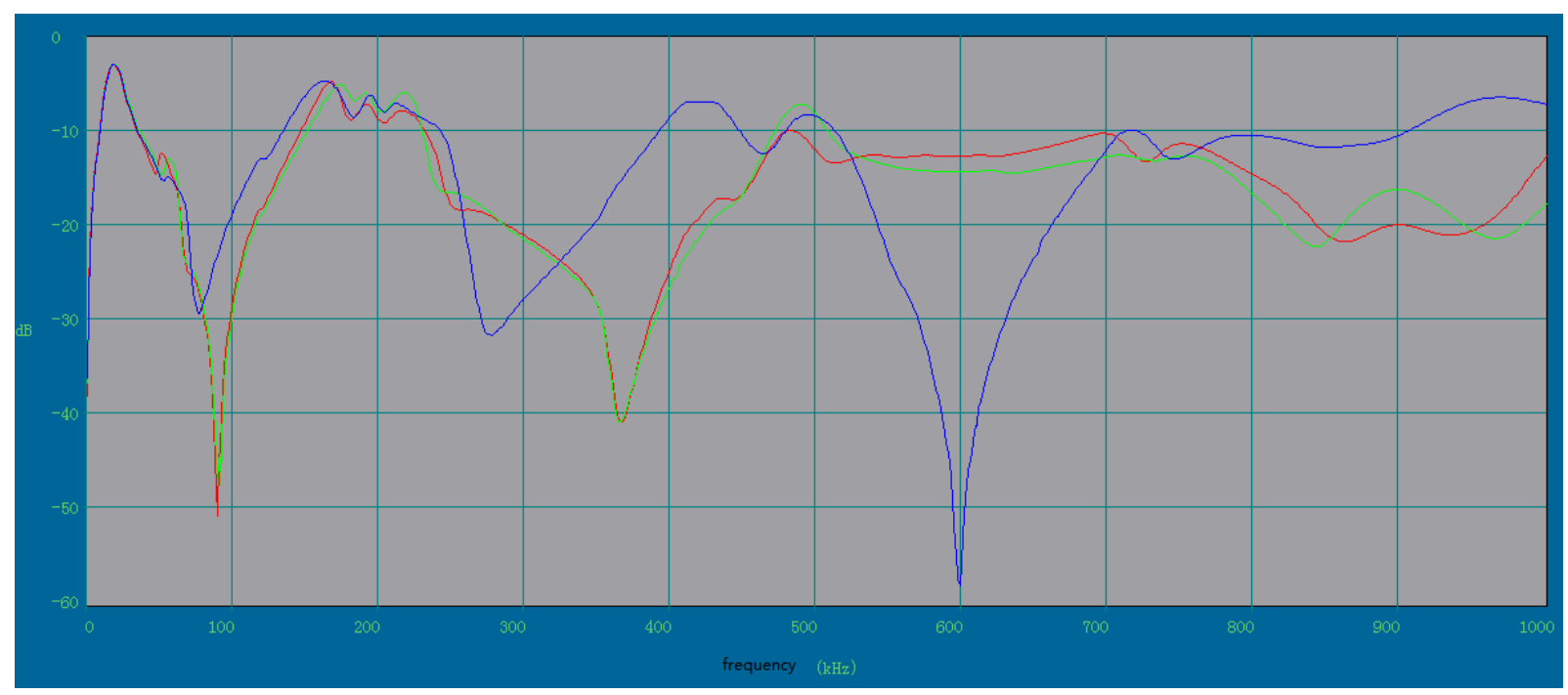

Figure 1 The frequency response curve for the main transformer of the three phase

\section{The test oil chromatogram}

Sampling for transformer to the chromatographic analysis on the night, finding the oil contains $12.46 \mu \mathrm{L} / \mathrm{L}$ acetylene, total hydrocarbon $24.69 \mu \mathrm{L} / \mathrm{L}$, before the accident the total hydrocarbon $3.95 \mu \mathrm{L} / \mathrm{L}$, acetylene $0 \mu \mathrm{L} / \mathrm{L}$, the diagnosis of the transformer is the internal electrical fault.

Analysis of the data can be seen from the oil chromatogram, after the No. 2 main transformer suffered the outlet short-circuit fault, producing the internal arc discharge. According to the above analysis, it can think of the $10 \mathrm{kV}$ low voltage $\mathrm{C}$ phase winding suffered short-circuit current impact, resulting the winding deformation, the part winding distortion may cause inter turn、 interlayer 
short-circuit, with the arc discharge. The transformer in the field has not repair, and it must return back to factory for repairing.

\section{Disintegration and return to the factory for inspection}

According to the test results, Fushun power supply company organize manufacturers personnel and the relevant experts for disintegration and inspection of returning the factory cover lifting on the transformer, after the transformer cover lifting, the appearance of the various parts of the high voltage winding are no abnormal phenomenon. The low voltage side c phase winding deformation is the most serious (Figure 2a), in the iron core, the axial electric power role in the iron core structure, the iron core structure occur the emergence of instability and deformation (Figure 2b), the transformer suffer the sudden short-circuit, the high and low voltage side are subjected to short-circuit current impact, when the circuit breaker is not broken in a very short time, the short-circuit current generate the electric power of the current is proportional to square role in the transformer winding, the electric power can be divided into radial force and axial force. In short-circuit, the radial force rolling in the winding will make the high voltage winding is subjected to tension impact; the low voltage winding is subjected to pressure impact. Because the winding is circular, the circular object is more easy deformation under pressure than under tension, so the low voltage winding is easily deformation. The axial force generated in the sudden short-circuits make winding compression and make the high and low voltage winding happens axial displacement, the axial force also role in the iron core and clamps. So the transformer in suffered sudden short circuit, the most prone to deformation is the low voltage winding, and then is the high voltage winding, iron core and clamp.

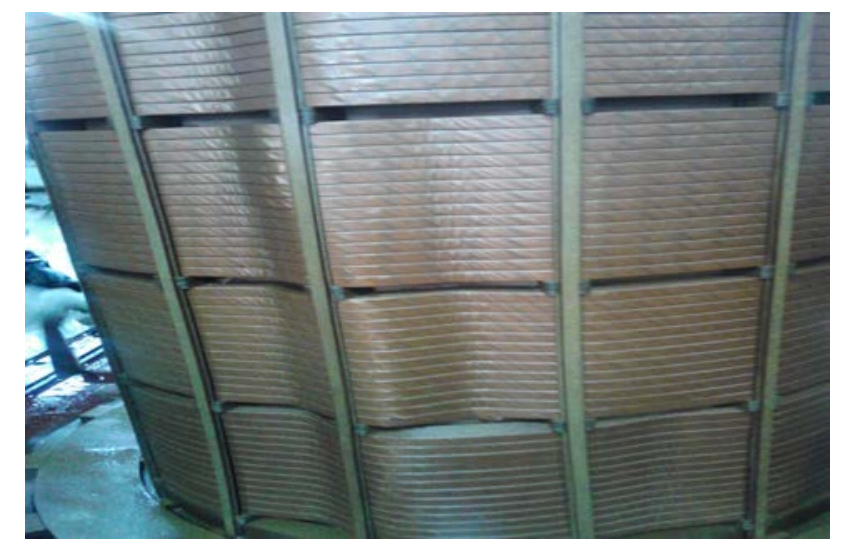

a. Low voltage side c phase winding deformation is most serious

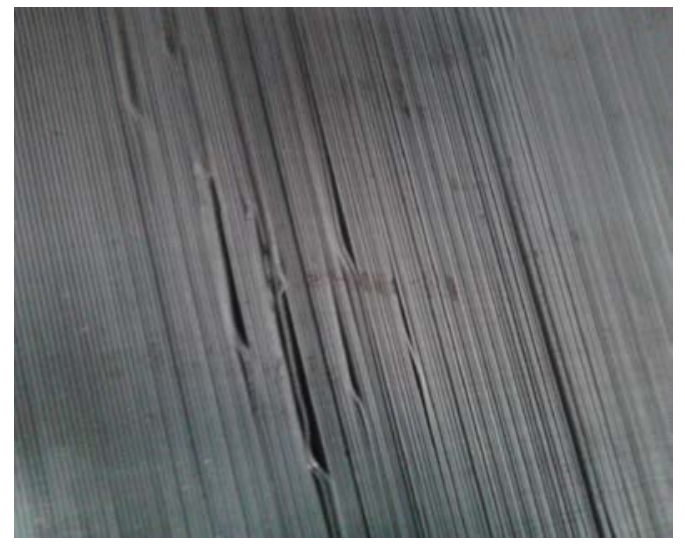

b. Iron core structure instability and deformation

Figure 2 Transformer cover strip inspection returned to the factory

\section{Conclusions}

1) The winding capacitance is related to the size, relative position and the insulating medium, the winding equivalent capacitance directly reflects between the different windings the windings on the iron core 、 the windings on the relative position of the box body and ground and the winding its structure etc.. .When the winding has the relative displacement, changing the capacitance, which can determine whether the structural change, the serious deformation will lead to the winding capacitor values change significantly, generally the measured capacitance value compare with the historical data, the difference is greater than $10 \%$, the winding may have occurred moderate partial light shape; more than $15 \%$, the transformer internal may exist serious deformation. It should immediately do the winding deformation test and the partial discharge test, to determine whether the transformer can continue to operation. In general, the transformer moderate deformation cannot support the next outlet short-circuits impact. 
2) The short-circuit impedance method as the concise and quantitative criterion , each transformer in factory also has the original test values of the short-circuit impedance for comparison, and the professional level of the short-circuit impedance test method for the test personnel is not high, so it is easier to implement and grasp in the field. But there are large capacity of the test power source and heavy equipment and other factors.

3) the frequency response analysis method on the field can sensitive response and detect for the winding deformation fault, it detects the winding deformation phenomenon of the equivalent to short-circuit impedance change to $0.2 \%$ or the axial size change to $0.3 \%$ for the transformer without the cover lifting. Its test using the sweep frequency technique, it outputs the amplitude and frequency of the known sine wave signal, is advantageous for the use of the digital signal processing technology to eliminate the influence of the interference signal, the measured spectrum is more stable, but because of the frequency response method is interfered by many factors, the diagnosis is a huge amount of uncertainty.

In conclusion, for the transformer winding deformation test, should be contrasted with the many kinds of test means, especially using the combination of the low voltage impedance test and the frequency response test, and test validated with the capacitance of the conventional test each other, play advantage and their test methods complement each other, it can make the low transformer winding deformation test 、 analysis and judgment more complete and accurate, so as to grasp the transformer windings working state in time, in order to reduce the probability of accidents, ensure the safe and stable operation of power grid.

\section{References}

[1] Han Aizhi. The simple method of judging transformer winding deformation, transformer, 2003]

[2] Frequency Response Analysis Method of Power Transformer Winding Deformation. DL/T911, 2004

[3] Ying Wei. Overhead transmission line condition-based maintenance and practical technology. China Electric Power Press, 2004

[4] Chen Tianxiang, Wang Yinzhong. Electrical Test. Beijing: China power press, 2010

[5] Three live working procedures. China Electric Power Press, 2003. 